\title{
Study on Social Media is an Effective Platform to Use When Recruiting
}

\author{
Hou Bingjie ${ }^{1, a}$ and Xing $\mathrm{Li}^{1, b}$, * \\ ${ }^{1,}$ College of Economy and Management, Longdong University, Gansu, 745000 \\ a monkeybr@126.com, ${ }^{b}$ lixing@ldxy.edu.cn \\ * The Corresponding author
}

\begin{abstract}
Keywords: Social media; Human resources; Recruit; Case study
\end{abstract}
\begin{abstract}
Social media is an important and upcoming topic in HR departments. Especially, the networking scope of the Social Networking Sites is the most predicting factor for effective recruitment, in particular for the target group orientation, which are younger generation and graduates. By using literature research method, there are 22 literature from 2007 to 2013 in this study, which include different countries' findings among American, British, German and Irish companies to attract and recruit potential candidates with social media. In addition, this study tests that social media as an effective channel challenged the traditional recruitment methods at present, because it is beneficial to build employer brand, reduce recruiting cost and save recruiting time for companies, it is faster to gain the response from candidates, especially it provides more opportunities for smaller firms, and HR professionals might learn more information which were not on the list of curriculum vitae or application form, such as criminal behavior, illegal activities and ethical issues. Furthermore, social media is a significant approach to attract and recruit applicants, engage employees and retention staffs for companies.
\end{abstract}

\section{Introduction}

Alone with the development of technology, social media caused widely concern, and it is widespread in the world, because there is no limitation by geography, culture, region, age and so on. "The concept of social media is top of the agenda for many business executives today" (Kaplan and Heinlein, 2010, p59). Although people have interest on social media, there are a few exact definition or understanding about it. "Social media is the collective of online communications channels dedicated to community-based input, interaction, content-sharing and collaboration" ("social media", 2013).

According to Kaplan and Heinlein (2010, p62-64), there were six different types of social media: collaborative projects ( like Wikipedia), blogs and microblogs ( like Twitter), content communities (for example, YouTube and DailyMotion), social networking sites (like Facebook), virtual game worlds ( like World of Warcraft), and Virtual social worlds (like Second Life). Also, there were more than 175 million active users on Facebook by January 2009, 10 hours of content were uploaded to the video sharing platform YouTube in every minute, and the image hosting site Flickr provided access to over 3 billion photographs at the same time (Kaplan and Heinlein, 2010, p59). "According to Forrester research, 75\% of Internet surfers used social media in the second quarter of 2008 by joining social networks, reading blogs, or contributing reviews to shopping sites, which have a significant rise from 56\% in 2007" (Kaplan and Heinlein, 2010, p59). Therefore, the usage of social media reveal a revolutionary new trend that organisations were interested in using the new platform when recruiting. However, this study focused on social networks sites. In addition, it focus on building employer brand, which social media is one of important methods to attract and recruit potential candidates, especially for younger generation or graduates. Hence, this review explored and identified whether social media is an effective method to use when recruiting by a good deal of research on NTU online library, CIPD, Emerald and so forth. Also, some key items were researched, such as "what is social media", "use social media to recruit", "impact of social media for recruitment". 


\section{Literature Review}

Social media as a technology advances and a new channel to recruit, which broke the traditional methods when hiring, for example cover letter, curriculum vitae, application form, and interview. It rapidly expanded on popularity, and their potential utility has also risen. However, different people have different views about using social media to recruit.

Kate (2009) revealed the trend for young graduates (Generation Y) to seek job by social media is sure in the future, hence, organisations absolutely need to take part in social media to develop employer brand to attract and recruit candidates. Also, the information from social media might be vital to applicants to consider and make decision whether they would like to work in the company. Besides, social media has been a popular and crucial external communication channels to show the brand images for companies, and using social media is significant to connect and keep young high potentials.

Slovensky and Ross (2012) examined the reasons why HR manager should use social network web sites (SNWs) to hire applicants in USA. First, SNWs might provide honest, accurate and truthful applicant information. Applicants always only highlight their positive characteristics in traditional recruitment methods, such as curriculum vitae, cover letters, application forms, telephone or face-to-face interview and so forth (Barrick, Shaffer and DeGrassi, 2009). SNWs could offer different perspectives about the job candidates from friends, classmates, families and so on (Goodman, 2010). These information might be more credible than from themselves for HR professionals to make decisions. Second, SNWs may help HR managers use a cost-effective approach to have more comprehensive view about every candidates. For example, in Facebook, HR professionals might learn more information which were not on the list of curriculum vitae or application form by photos or videos. Last, SNWs could prevent some "negligent hiring" for organisations. HR professionals might find out some criminal behavior, illegal activities or a person who will embarrass or endanger fellow employees or customers on SNWs, hence, it will avoid the risk to recruit applicants who have legal and ethical considerations.

Ollington, Gibb, and Harcourt (2013) conducted a study to investigate that the use of online social networks for recruiters. There were 25 recruitment specialists in total with 60 or 90 minutes interview each person to collect the data. They believed that online social networks were positive tool to attract and screen potential candidates. In addition, there were $90 \%$ of participants used LinkedIn and 70\% used Facebook to attract job seekers. What is more, the participants stated that connector, brand, transparency of data and data specificity are key factors to use online social networks effectively to attract and screen potential candidates. In other words, recruiters play a significant role to tie job seekers. In order to attract potential applicants, they post their organisation's image, goals, values or brand on the online social networks; make sure that recruiters have access to all web sites which related to candidates, and make the job data and information clear and accurate. There are $82 \%$ of employers recruit via online job boards, while $54 \%$ of them use social media.

Lohse (2013, p69) examined that Facebook is a effective strategy to recruit low earning women to online nutrition education program through posting advertising and surveys on Facebook page. The reason why using social media sites to recruitment is the fact that there is no limitation by earning, education or geography on internet (p69). There were $86 \%$ of adults who are age from 18 years old to 29 years old using social media sites (p69), and 66\% of them used Facebook. Also, $80 \%$ of low-income people in Pennsylvania had internet access, and they believed that the internet is the most convenient way to gain health information (p69).

On the other hand, others concerned some problems which caused by social media, such as legal and ethical issues. Also, social media sites would be monitored or banned, especially in workplace, so that it protect the benefits of individuals and organisations.

According to Schauble et al. (2008), using social media to recruit cause changes and challengers for the Human Resource departments and organisations. In order to work with such new technologies for social media, recruiters have to take time and energy to study and familiar with it. In addition, organisations must define data protection regulations and user regulations for the use of 
these sites. Also, it is essential that supervise some possible issues for applicants, such as discrimination, illegal and ethical problems.

According to research from software security firm Clearswift (Churchard, 2011), managers who block employees access to social media sites such as Facebook and Twitter at work was increasing, which from $9 \%$ in 2010 to $19 \%$ in 2011 . In addition, the research showed that there were $68 \%$ firms monitor the internet activities of their employees, and almost half organisations block employees use social media sites. Security and data loss are concerned by $91 \%$ of UK businesses, and nearly half employers stated there is an management issue via using social media. An increasing number of employers preferred block the use of Facebook and twitter rather than encourage staff to use it. The usage of social media in work not only have security risk, but also it likely to have affect on concentration of staff.

Wallis (2011) examined that employees' misuse of social media could damage business benefits. If employees have some abusive behaviour and inappropriate comments about colleagues, employers and customers on LinkedIn, Facebook or twitter, it will damage business reputation and employer brand building. There are some examples as followings: a pub manager communicated with customers using insulting language and complained the customers on Facebook while working; a flight attendant posted indecent photos on her blog, which she wore the uniform and leaned over a seat to show some of her underwear; staff discussed some confidential issues and information of organisations on Facebook; an employee posted a video about flighting between his two colleagues on YouTube (Wallis, 2011). All the individual behaviour would impact organisations' image, and have a negative effect to build employer brand and attract and recruit candidates via using social media.

Churchard (2011) stated that approximately one third of managers have managed employees for inappropriate behaviour on social media sites, although the majority of employees have been actively encouraged to use social media for work. The first reason is that employees might post some confidential information related work on social media sites, because some employees do not know how to set and protect the information on their personal and organisations' social media sites. Secondly, former employees still could research and enter social media sites of organisations, then they are easy to get some information about clients when they leave the organisation, it is a risk to attract and recruit new staff for organisations. Also, there are some private issues. For example, nurse posted some photographs or have some comments about patients on social media sites, like Facebook, which violate the privacy right of patients (Steven, 2011). In order to protect confidential information and the risk, organisations might invest more on the security software (Smedley, 2012). Although some firms banned staff to use social media sites, such Facebook, Twitter, LinkedIn and so forth on work with their work computers, they also could use it with their smartphone. Therefore, social media sites could influence and reduce the efficiency and effectivity at work (Smedley, 2012).

Slovensky and Ross (2012, p11) considered against using SNWs when recruiting as followings: SNWs information does not accurately reflect what the applicant will be like as an employee, because candidates' behaviour are different between at work and out the workplace; a wrong SNW might be looking by the employer, since many names are similar in the same place in Twitter, LinkedIn, Facebook and so forth; the aims of job applicants post information on their SNWs and employers search it are different, which may cause fairness concerns; it might merely reinforce initial decisions with SNW information, which include curriculum vitae and cover letters; the privacy of candidates may be violated by searching SNWs; and searching SNWs leds to numerous legal and ethical issues, especially in the area of American Equal Employment Opportunity law.

According to Miller (2013), there were disciplines in government to use social media sites since 2009. "Eleven civil servants at the Department for Work and Pensions (DWP) of UK have been sacked for misusing Twitter or Facebook" (Miller, 2013). DWP staff just allowed access to Twitter on their computer, they were constrained to use Facebook or other social media sites in the workplace. Some might have a warning, and some would be fired directly if they violate the policy. Besides, there is a clear guideline to help DWP staff to use internet and social media, and most of 
the staff abide by the rules and penalties. It will be a potential factor to impact the recruitment of younger generation.

\section{Conclusion}

Social networks site (SNSs) such as Facebook, Twitter, Linkedin, as a vital communication tool have connected individuals and organisations. It have attracted millions of users many of whom have integrated these sites into their daily practices (Boyd and Ellison, 2008). Social media has the most powerful influence on effective recruitment, in particular on the target group orientation. However, it has both positive and negative effect for individuals and organisations. Whether social media is an effective channel when recruiting, organisations will value it by practices and management in reality. Anyhow, social media as a technology advanced method to recruit applicants for companies is beneficial to build employer brand, reduce recruiting cost and save recruiting time for companies, it is faster to gain the response from candidates, especially it provides more opportunities for smaller firms, and HR professionals might learn more information which were not on the list of curriculum vitae or application form, such as criminal behavior, illegal activities and ethical issues. In addition, for candidates and companies, it is a true, easy and accurate way of choosing each other. Furthermore, social media is a significant approach to attract and recruit applicants, engage employees and retention staffs for companies.

\section{Reference}

[1] Abel, S. (2011) The role of Social Networking Sites in recruitment: Results of aquantitative study among German companies. Netherlands: University of Twente.

[2] Brockett, J. (2011) News review 2011: Social media. CIPD. 21 December, available at:http://www.cipd.co.uk/pm/peoplemanagement/b/weblog/archive/2011/12/21/news-review-of2011-social-media-2011-12.aspx (accessed 4 September, 2013).

[3] Li,Xing; YangZihan;HouBingjie,Analysis of Internal and External Factors Affecting the Development of Cross-Strait Cultural and CreativeIndustries[J],Advances in Social Science Education and Humanities Research.2016,(77)pp:151-155

[4] Li X., Qu T., He J.M., Hou B.J.,Seek Excellence on the Hospital Quality Management Competition[J],Basic \& Clinical Pharmacology \& Toxicology,2016,December, Volume 119, Issue S4,HHME16-H24

[5] Slovensky,R. And Ross, W.H. (2012) "Should human resource managers use Social media to screen job applicants? Managerial and legal issues in the USA", info, Vol. 14 Iss: 1, pp.55 - 69

[6] Welinder, E. (2012) Google is the world's most attractive employer. Universum. Availableat:http://universumglobal.com/wpcontent/uploads/2013/07/WMAE_2012pressrelease. pdf (accessed 5 september, 2013)

[7] Xing Li, Qiu Wenhong, Zhang Peiyao, and. Discussion on service innovation of cultural and Creative Park: cultural value perspective [J]. macroeconomic management, 2017, (S1): 34-36. 